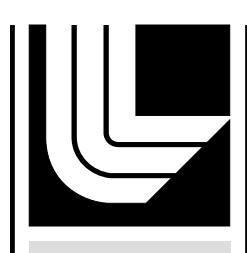

LAWRENCE LIVERM ORE NATIONAL LABORATORY

Mesoscale Simulations of a Wind Ramping Event for Wind Energy Prediction

M. Rhodes, J. K. Lundquist

October 4, 2011 
This document was prepared as an account of work sponsored by an agency of the United States government. Neither the United States government nor Lawrence Livermore National Security, LLC, nor any of their employees makes any warranty, expressed or implied, or assumes any legal liability or responsibility for the accuracy, completeness, or usefulness of any information, apparatus, product, or process disclosed, or represents that its use would not infringe privately owned rights. Reference herein to any specific commercial product, process, or service by trade name, trademark, manufacturer, or otherwise does not necessarily constitute or imply its endorsement, recommendation, or favoring by the United States government or Lawrence Livermore National Security, LLC. The views and opinions of authors expressed herein do not necessarily state or reflect those of the United States government or Lawrence Livermore National Security, LLC, and shall not be used for advertising or product endorsement purposes.

This work performed under the auspices of the U.S. Department of Energy by Lawrence Livermore National Laboratory under Contract DE-AC52-07NA27344. 


\title{
Mesoscale Simulations of a Wind Ramping Event for Wind Energy Prediction
}

\author{
Michael E. Rhodes ${ }^{1}$ and Julie K. Lundquist ${ }^{2}$ \\ ${ }^{1}$ Department of Aerospace Engineering \\ ${ }^{2}$ Department of Atmospheric and Oceanic Sciences \\ University of Colorado at Boulder \\ Interim report on a subcontract from 15 May 2010 to 1 March 2011 \\ Work preformed for Lawrence Livermore National Laboratory
}

\begin{abstract}
Ramping events, or rapid changes of wind speed and wind direction over a short period of time, present challenges to power grid operators in regions with significant penetrations of wind energy in the power grid portfolio. Improved predictions of wind power availability require adequate predictions of the timing of ramping events. For the ramping event investigated here, the Weather Research and Forecasting (WRF) model was run at three horizontal resolutions in "mesoscale" mode: 8100m, 2700m, and 900m. Two Planetary Boundary Layer (PBL) schemes, the Yonsei University (YSU) and Mellor-Yamada-Janjic (MYJ) schemes, were run at each resolution as well. Simulations were not "tuned" with nuanced choices of vertical resolution or tuning parameters so that these simulations may be considered "out-of-the-box" tests of a numerical weather prediction code. Simulations are compared with sodar observations during a wind ramping event at a "West Coast North America" wind farm. Despite differences in the boundary-layer schemes, no significant differences were observed in the abilities of the schemes to capture the timing of the ramping event. As collaborators have identified, the boundary conditions of these simulations probably dominate the physics of the simulations. We suggest that future investigations into characterization of ramping events employ ensembles of simulations, and that the ensembles include variations of boundary conditions. Furthermore, the failure of these simulations to capture not only the timing of the ramping event but the shape of the wind profile during the ramping event (regardless of its timing) indicates that the set-up and execution of such simulations for wind power forecasting requires skill and tuning of the simulations for a specific site.
\end{abstract}




\section{Introduction}

Although wind energy capacity is rapidly increasing in the United States and around the world, managing the integration of this fluctuating power sources into power grids designed for scheduled production requires new technological approaches. Because electric utility companies usually have a specific generation configuration, which may consist of a mix of coal, natural gas, hydropower, and wind power, any change in the power generated by the wind requires an accompanying change in another power source. "Ramps", or rapid increases or decreases in power availability from the wind, are caused by rapid changes in the wind due to a range of meteorological phenomena including frontal passages, thunderstorm outflow, topographically-induced flows such as sea breezes and density currents, among others. Ramping events can occur regularly; an investigation by Kamath et al. (2010) find that, in the Bonneville Power Administration territory, that the as wind generation increases, larger ramps become more common. To ensure that adequate power will be available to fulfill demand even in the case of wind speed decreases that "ramp down" available power, operating utilities frequently maintain a spinning reserve of gas turbine generators running ready to fill any gap. Spinning reserves are typically quite expensive and tend to increase carbon dioxide emissions. Therefore, utility companies and wind farm owner/operators experience a need to forecast, with accuracy, the likelihood of a ramping event to ensure that minimal spinning reserves are maintained. The status of wind power forecasting in the North America is summarized in Porter and Rogers (2010).

As Porter and Rogers discuss, numerical weather prediction models like the Weather Research and Forecasting (WRF) model are in widespread use for wind power prediction. WRF is presented and discussed in detail in Skamarock and Klemp (2008). There is no clear-cut description of an optimal configuration of WRF for wind energy prediction; investigations like Storm et al. (2009) find inadequacies in all available parameterizations, particularly for investigations of phenomena critical for wind energy such as the nocturnal low-level jet. For the present investigation into one ramping event, WRF was run at three horizontal resolutions: $8100 \mathrm{~m}, 2700 \mathrm{~m}$, and $900 \mathrm{~m}$ with one of two Planetary Boundary Layer (PBL) schemes, the Yonsei University (YSU) or the Mellor-Yamada-Janjic (MYJ). The three horizontal resolutions were run simultaneously using one-way nesting such that the boundary conditions for each higherresolution grid ("nested grid") are taken from the solution on the lower-resolution grid ("coarse grid"). The same PBL scheme was used in all grids within a given simulation.

The purpose of this report is to compare "out-of-the-box" WRF model runs using the two PBL schemes with sodar observations during a wind ramping event at a West Coast North America wind farm. Model and sodar data are compared at different heights for a 48-hour time period encompassing the ramping event. The sodar data include measurements of three-dimensional 
wind speed and standard deviations of each wind component $(U, V, W)$. Each data stream is calculated from $20 \mathrm{~m}$ up to $200 \mathrm{~m}$ in $10 \mathrm{~m}$ intervals; additionally, the sodar data are averaged in time using a ten minute interval. It is apparent, especially at higher altitudes, that there are significant gaps in the sodar data that are likely due to unfavorable atmospheric conditions for signal return such as neutral stability or precipitation. Each PBL scheme is run at three different horizontal resolutions, and two heights from the model output correspond to the reported sodar heights ranging from $60 \mathrm{~m}$ to 180 meters above ground level (AGL).

This report consists of the following components. First, the WRF simulations are summarized, including choices of boundary conditions, surface representation, and physics options. Second, the meteorology of this ramping event is briefly summarized. Third, comparisons of the simulations with the available sodar data are presented, where we find that there is no clear indication of which PBL scheme may be optimal for this ramping event. Finally, conclusions are summarized, and we suggest avenues for future research.

\section{WRF Simulations}

The WRF simulations here were intended to represent, as much as possible, simulations by a naïve user "out of the box" without significant tuning for the site at hand (as a comparison to the more nuanced choices made by other members of the collaboration). Default choices of vertical profile and most physics options were used. The WRF simulations were initialized with data from the North American Regional Reanalysis, provided by the National Center for Atmospheric Research. This reanalysis product integrates observations, including precipitation data, radar profiler data, and numerous land surface and moisture datasets with forecasts for an "optimal" set of boundary conditions. The NCEP North American Regional Reanalysis products are on Eta 221 grid ( $32 \mathrm{~km}$ horizontal resolution) at 29 pressure levels. The output analyses are 3-hourly with additional 9 variables in the 3-hour forecasts to reflect accumulations or averages. Topography within the WRF domains is represented at approximately $1 \mathrm{~km}$ resolution using the "30 second" topographic and land use/land cover characteristics databases included with WRF distributions. WRF version 3.2 (released March 2010) was utilized for the simulations presented here. The two sets of simulations presented here differ only in the choice of PBL scheme (bl_pbl_physics) and surface layer scheme (sf_sfclay_physics). The simulations used identical choices for other physics options of land surface model (RUC), cumulus parameterizations (none), longwave and shortwave radiation. It was thought that the PBL schemes would have the most impact on the predictions of boundarylayer winds, although subsequent investigations may question that assumption given the negligible difference found here. 


\section{Meteorological Conditions}

A high pressure system dominated the region under investigation during the ramping event. Surface reanalysis maps indicate the high pressure system was located to the North-West of the wind farm. A ridge extended from the high pressure center to the South-East, and the ridge axis intersects the wind farm. Similarly, a $500 \mathrm{mb}$ reanalysis shows the high pressure system directly west of the wind farm. Maps are not shown in order to not reveal the location of the wind farm. Over the course of the two days under consideration, the high pressure system moved out to the east.

\section{Results}

As discussed in Porter and Rogers (2010), several metrics are conventionally-used to quantify the performance of a wind power forecast. The most common is the Root Mean Squared Error (RMSE), which is calculated by differencing observations from forecasts and squaring the difference, and summing up over all data points. To quantify the performance of each PBL scheme, RMSE is calculated for wind speed and wind direction. The RMSE was calculated between a particular model output and the sodar observations over the 48 hour period containing a wind ramping event. RMSE is calculated for both PBL schemes at the three resolutions and each height for that resolution. Table 1 lists calculated RMSE values for wind direction. Table 2 lists RMSE values calculated for horizontal wind speed.

Table 1: RMSE calculated from observed and modeled wind directions.

\begin{tabular}{|c|c|c|}
\cline { 2 - 3 } \multicolumn{1}{c|}{} & $\begin{array}{c}\text { RMSE } \\
\text { (degrees) }\end{array}$ & $\begin{array}{c}\text { RMSE } \\
\text { (degrees) }\end{array}$ \\
\hline Resolution & YSU & MYJ \\
\hline $\begin{array}{c}900 \mathrm{~m} \mathrm{@} \\
110 \mathrm{~m}\end{array}$ & 41.0 & 32.9 \\
\hline $\begin{array}{c}900 \mathrm{~m} \mathrm{@} \\
180 \mathrm{~m}\end{array}$ & 16.5 & $\mathbf{1 4 . 3}$ \\
\hline $\begin{array}{c}2700 \mathrm{~m} @ \\
100 \mathrm{~m}\end{array}$ & 45.8 & 37.2 \\
\hline $\begin{array}{c}2700 \mathrm{~m} @ \\
170 \mathrm{~m}\end{array}$ & 30.6 & $\mathbf{2 1 . 7}$ \\
\hline $\begin{array}{c}8100 \mathrm{~m} @ \\
60 \mathrm{~m}\end{array}$ & 53.4 & 45.1 \\
\hline $\begin{array}{c}8100 \mathrm{~m} @ \\
130 \mathrm{~m}\end{array}$ & 42.1 & $\mathbf{3 5 . 8}$ \\
\hline
\end{tabular}

Table 2: RMSE calculated from observed and modeled wind speeds.

\begin{tabular}{|c|c|c|}
\cline { 2 - 3 } \multicolumn{1}{c|}{} & $\begin{array}{r}\text { RMSE } \\
\text { (m/s) }\end{array}$ & $\begin{array}{c}\text { RMSE } \\
\text { (m/s) }\end{array}$ \\
\hline Resolution & YSU & MYJ \\
\hline $\begin{array}{c}900 \mathrm{~m} @ \\
110 \mathrm{~m}\end{array}$ & $\mathbf{3 . 2 9}$ & 4.64 \\
\hline $\begin{array}{c}900 \mathrm{~m} @ \\
180 \mathrm{~m}\end{array}$ & 5.25 & 5.77 \\
\hline $\begin{array}{c}2700 \mathrm{~m} @ \\
100 \mathrm{~m}\end{array}$ & 3.56 & 3.91 \\
\hline $\begin{array}{c}2700 \mathrm{~m} @ \\
170 \mathrm{~m}\end{array}$ & 6.28 & 5.93 \\
\hline $\begin{array}{c}8100 \mathrm{~m} @ \\
60 \mathrm{~m}\end{array}$ & $\mathbf{2 . 3 1}$ & 2.67 \\
\hline $\begin{array}{c}8100 \mathrm{~m} @ \\
130 \mathrm{~m}\end{array}$ & 3.54 & 3.42 \\
\hline
\end{tabular}


At each resolution, for both wind speed and direction, the smallest RMSE value is emphasized with bold text, and smaller RMSE values indicate that the model output is closer to observations.

\section{Wind Direction}

The RMSE of wind direction varies between 14 degrees and 53 degrees. This range represents a significant error considering that this site typically experiences channeled flow (Wharton and Lundquist, 2010). The large RMSE of wind direction therefore suggests that the timing of the rotation of the wind vector that accompanies the ramping event is incorrect for both cases, as will be discussed below. However, when considering wind direction, MJY consistently performs better than YSU at all heights examined here. (YSU predicts the ramp incorrectly four hours early; MYJ predicts the ramp to be more gradual over several hours, but still early.) Errors tend to decrease as height increases. However, as shown in Figures 1 and $\mathbf{2}$, higher altitudes report fewer sodar data points; this paucity of data at high altitudes likely explains the lower RMSE value. Figure $\mathbf{3}$ has more sodar data available and lower RMSE values. Furthermore, the simulations with increased horizontal resolution also tend to have smaller RMSE values. It also shows that the change in wind direction associated with the ramp is captured by the model simulations, but the timing does not correspond to the timing observed by the sodar. While the model does capture the ramping event, the incorrect timing causes higher RMSE values. This mistiming also exists for both $8100 \mathrm{~m}$ model runs and both $2700 \mathrm{~m}$ model runs. The mistiming is more noticeable in the lower elevation plots as well, which could also potentially cause the higher RMSE values for lower heights.

\section{Wind Speed}

The incorrect timing of the ramp appears in the signature of the wind speed data as well as that of the wind direction data discussed above. Although wind direction appears to be more accurately forecast at altitude, wind speed is better modeled at lower altitudes regardless of horizontal resolution. Also, in contrast to the metrics based on wind direction, the wind speed metrics indicate that the YSU PBL scheme can be considered to slightly outperform the MYJ scheme. Both schemes clearly capture the wind speed peak at the beginning of the simulation (14UTC) and then continue to have similarly shaped and timed curves at each height. It is notable, that these two simulations also show that the simulations generally failed to accurately capture the magnitude of the wind speed change during the ramp. As seen in Figure 4, the ramping event observed wind speeds were nearly twice as large as the simulated wind speeds at $100 \mathrm{~m}$ above the surface. Further aloft, the pattern switches, and the predicted winds exceed the observed winds. Figure 6 shows that the observed wind speeds were lower than the modeled winds at $180 \mathrm{~m}$ above the surface. Note that, at this altitude, neither model appears to have captured the ramp. Difference of this order of magnitude exist for many of the other 
heights during the ramping event. We conclude that the shape of the wind profile during the ramping event is particularly poorly represented by the model setup under consideration here. Wind shear is likely to affect wind turbine productivity (Antoniou et al., 2009; Wharton and Lundquist, 2010), and this failure of the forecasting model to not only capture the timing of the ramping event but also the shape of the profile of the winds during the ramping event is significant.

The improved performance from YSU is most clearly seen in the finest mesoscale simulation, at $900 \mathrm{~m}$ resolution, shown in Figure 4, in which the YSU forecast more closely agrees with the increased wind speeds later in the simulation. The $900 \mathrm{~m}$ resolution simulation shown in Figure 4, and the $8100 \mathrm{~m}$ resolution simulation shown in Figure 5 indicate that the modeled ramp occurred at approximately 08 UTC on the first day of the simulation and leads the observed ramp, at approximately 16UTC, by 8 hours. Additionally, this figure shows that the YSU scheme better captured the ramping event than the MYJ scheme did. However, this was not true for all model runs. Figures 4 and $\mathbf{6}$ show that the YSU and MYJ schemes performed similarly for the simulation.

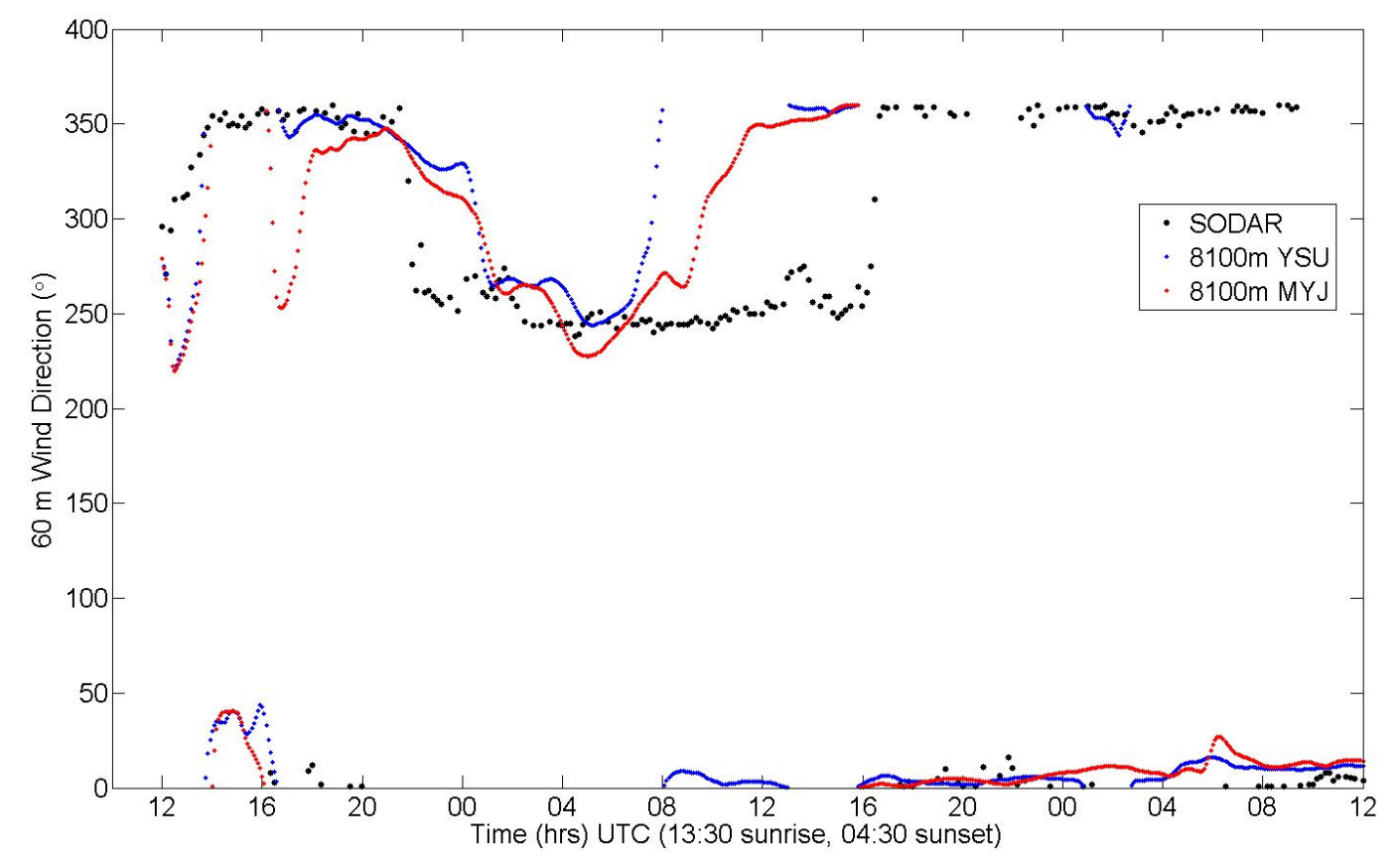

Figure 1: Wind direction at $60 \mathrm{~m}$ altitude for the 8100 meter horizontal resolution run. Sodar data return at this altitude is consistently good throughout the full 48 hour study. 


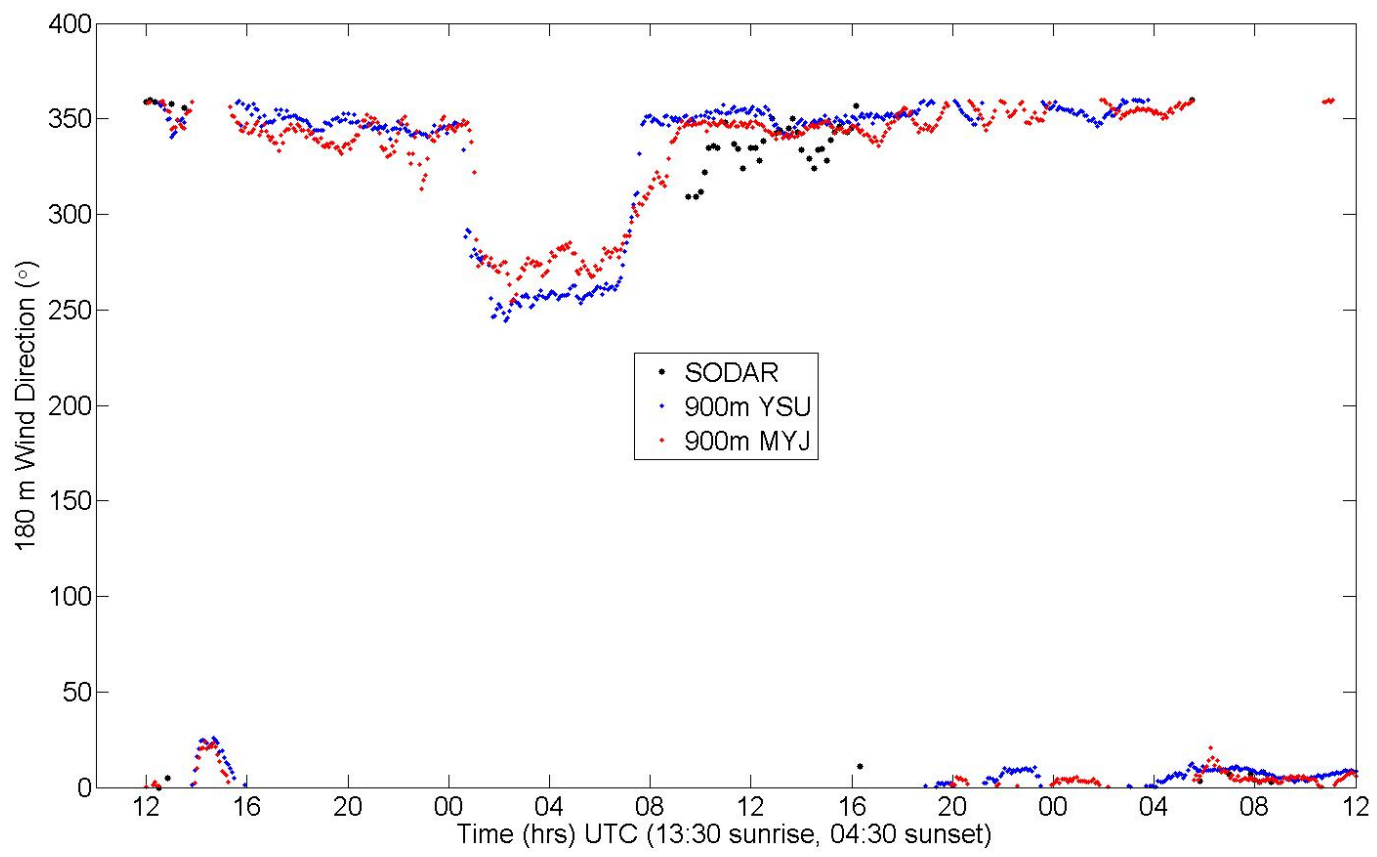

Figure 2: Wind direction at the $\mathbf{1 8 0} \mathrm{m}$ altitude for the 900 meter horizontal resolution run. Few sodar data points exist during the observed ramp at 16 UTC on the second day.

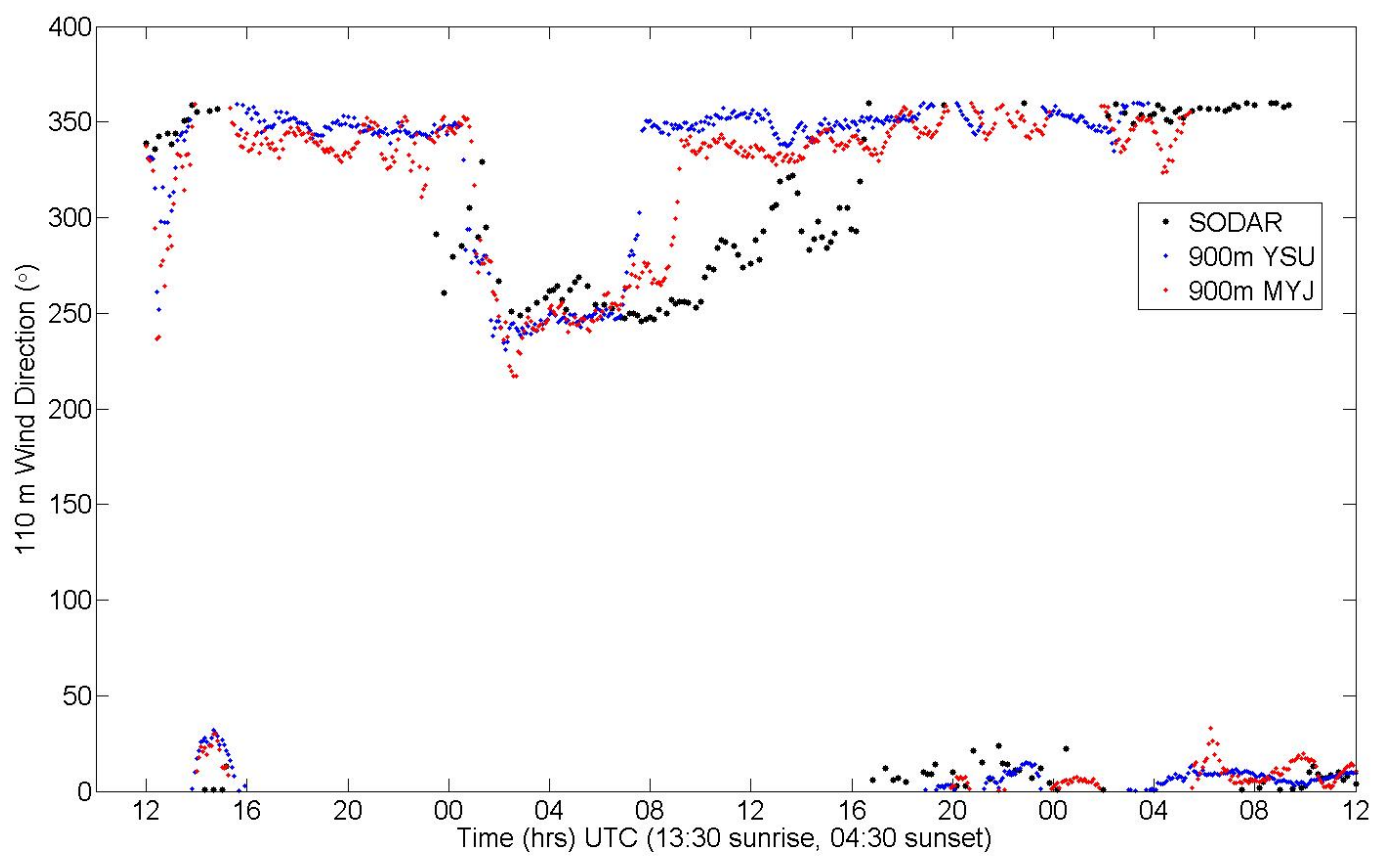

Figure 3: Wind direction at the $110 \mathrm{~m}$ altitude for the 900 meter horizontal resolution run. Both PBL schemes incorrectly forecast the wind shift associated with the ramping event by predicting it too early. 


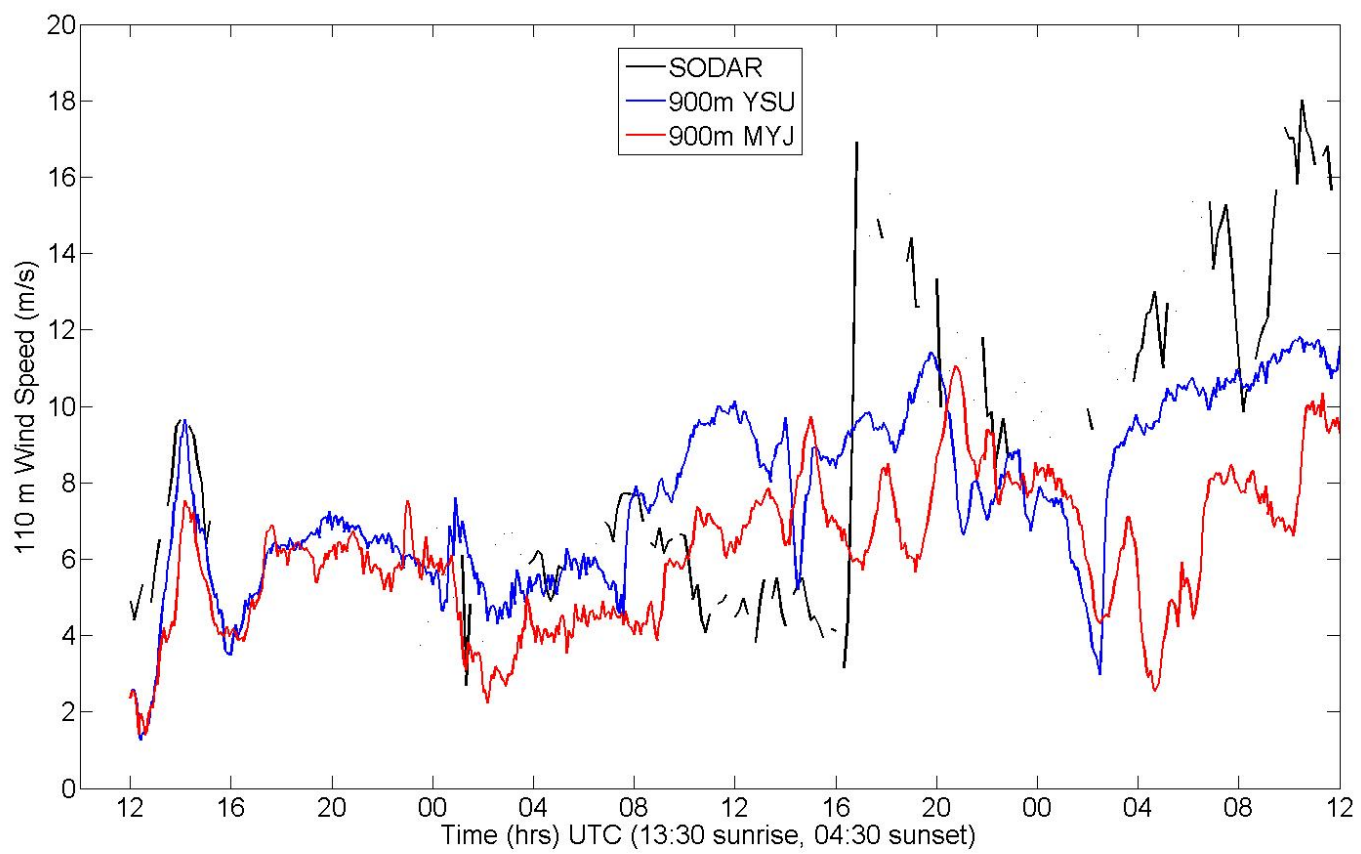

Figure 4: 110 meter wind speed from the $\mathbf{9 0 0}$ meter horizontal resolution run. The ramp does not show up significantly in the models when compared to other model heights and horizontal resolutions. Both PBL schemes follow the same trend in wind speed prediction; each scheme under predicts the maximum ramping wind speed by an approximate factor of 2 .

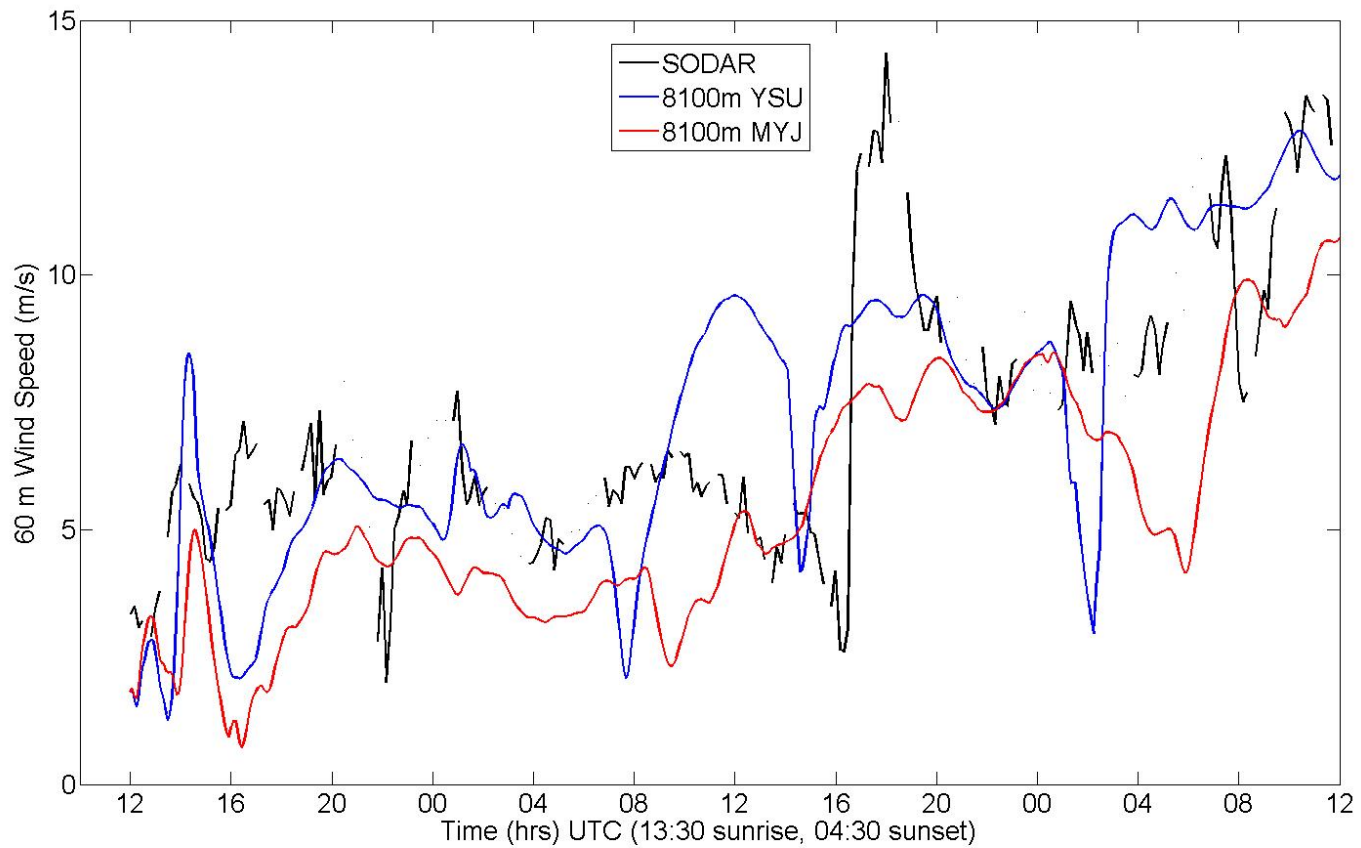

Figure 5: 60 meter wind speed from the $\mathbf{8 1 0 0}$ meter horizontal resolution run. The YSU PBL scheme predicts a ramp approximately 8 hours prior to the observed ramping event.

Rhodes \& Lundquist

Page 8 of 12 


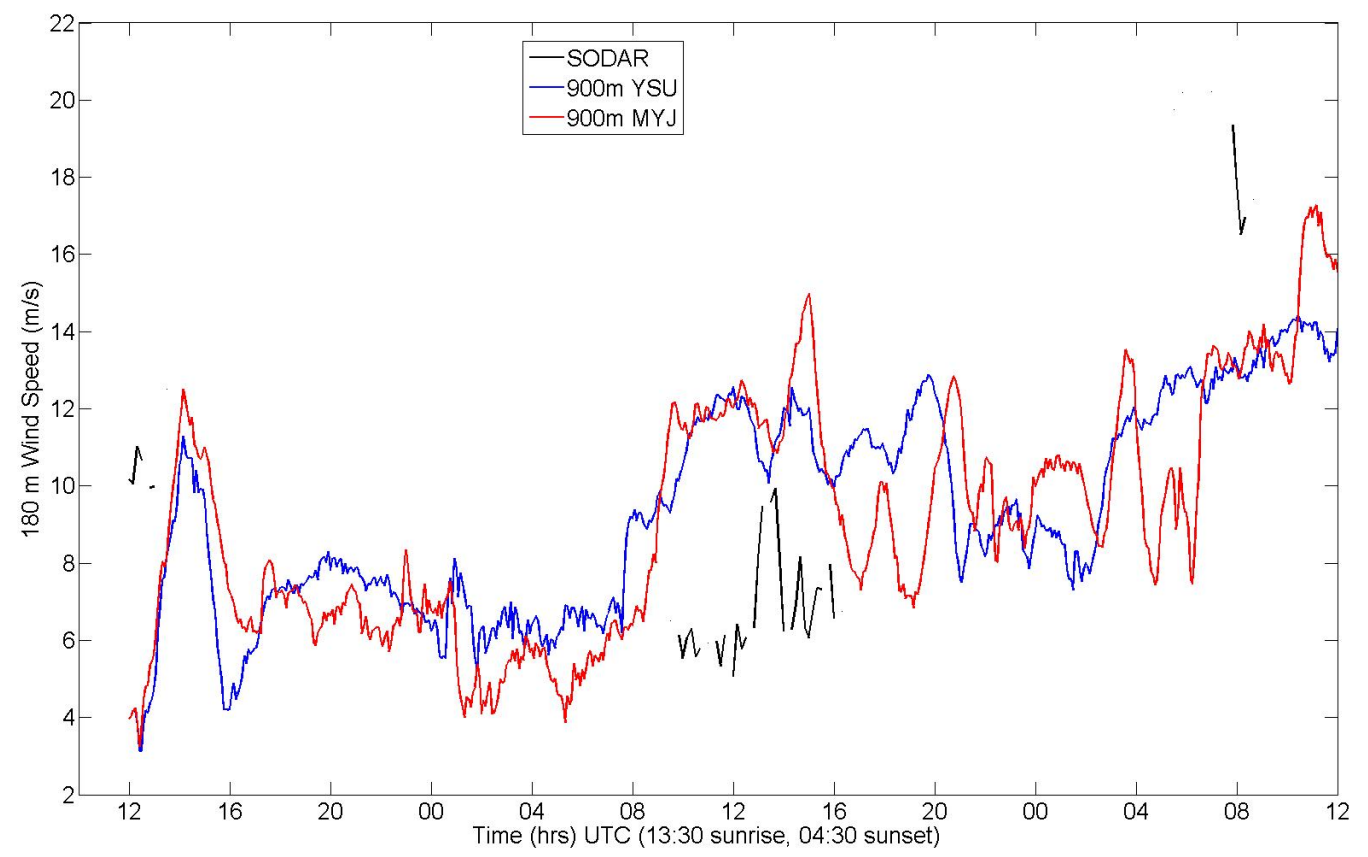

Figure 6: 180 meter wind speed from the $\mathbf{9 0 0}$ meter horizontal resolution run. Both PBL schemes follow the same trend in wind speed prediction. This includes an over prediction of wind speeds before the ramping event and under prediction of wind speed after the ramp.

\section{Conclusion}

In this study, we exercise the wind ramp forecasting capabilities of the WRF model with minimal tuning of model parameters. No adjustments to default WRF settings are made other than to change PBL and surface-layer schemes, and standard vertical resolutions and products for boundary conditions and surface characterization are employed. These simulations are intended as a comparison to more sophisticated simulations carried out by collaborators on this project to emphasize the critical role of skilled model set-up rather than "out-of-the-box" model execution.

It is clear that the performance of the model for this particular ramping event is suboptimal; the timing of the ramp is incorrectly forecast by several hours by simulations with either the MYJ or YSU PBL scheme, and increased horizontal resolution to the limit of the terrain resolution (1km) does not improve the forecast. The YSU PBL scheme shows a slight advantage in predicting total horizontal wind speed through the ramping event, while MYJ shows better agreement when wind direction is considered. It appears that finer resolution model runs are useful for 
capturing changes in wind direction, however better agreement is found at coarser resolutions when determining wind speed. This evaluation is complicated by incomplete sodar data availability, particularly at higher altitudes $(\sim 180 \mathrm{~m})$ during the ramping event. The poor performance of the simulations presented herein should not be considered an indictment of the capabilities of numerical weather forecasting for these applications, but rather as a warning of the importance of careful and skillful model set-up for each site of interest.

Most operational wind energy forecasting systems use refined resolution of the lower layers of the atmosphere (Lundquist, 2008; Porter and Rogers, 2010) to capture shallow surface-based phenomena poorly represented in these simulations. Ongoing improvements in PBL schemes focused on wind energy applications (Olson et al., 2011) will further enhance model skill in predicting winds at the altitudes relevant for wind-energy applications. Future evaluations of numerical weather predictions for ramp events can exploit recent developments in refined simulations including large-eddy simulation (Mirocha et al., 2011 and Liu et al., 2011) and data assimilation (Delle Monache et al., 2011).

\section{Acknowledgments}

The data for this study are from the Research Data Archive (RDA) which is maintained by the Computational and Information Systems Laboratory (CISL) at the National Center for Atmospheric Research (NCAR). NCAR is sponsored by the National Science Foundation (NSF). The original data are available from the RDA (http://dss.ucar.edu) in dataset number ds608.0. The WRF simulations were executed on high-performance computing facilities at the National Renewable Energy Laboratory; NREL is a national laboratory of the U.S. Department of Energy, Office of Energy Efficiency and Renewable Energy, operated by the Alliance for Sustainable Energy, LLC. The authors greatly appreciate the generosity of Iberdrola Renewables, Inc., for their provision of the meteorological data used herein. This work was done under subcontract \# B589952 for Lawrence Livermore National Laboratory. Lawrence Livermore National Laboratory is operated by Lawrence Livermore National Security, LLC, for the U.S. Department of Energy, National Nuclear Security Administration under Contract DE-AC52-07NA27344. 


\section{References}

Antoniou I., S.M. Pedersen, and P.B. Enevoldsen, 2009: Wind shear and uncertainties in power curve measurement and wind resources. Wind Engineering 33, 449-468.

Delle Monache, L., G. Descombes, B. Kosovic, M. D. Simpson, V. Bulaevskaya, M. Alai, and L. G. Glascoe, 2011: Ensemble data assimilation for wind energy applications. American Meteorological Society Second Symposium on the New Energy Economy, January 2011, Seattle, WA. Presentation available at http://ams.confex.com/ams/91Annual/webprogram/Paper185473.html

Kamath, C., 2010: Using Simple Statistical Analysis of Historical Data to Understand Wind Ramp Events. LLNL Technical Report LLNL-TR-423242, available at https://e-reportsext.Ilnl.gov/pdf/386189.pdf.

Liu, Y., et al., Simultaneous nested modeling from the synoptic scale to the LES scale for wind energy applications. J. Wind Eng. Ind. Aerodyn. (2011), doi:10.1016/j.jweia.2011.01.013

Lundquist, J.K., 2008: Director's Climate Initiative Wind Energy SMS Task - 2008 Report. LLNL Technical Report LLNL-TR-407754.

Mirocha, J. D., J. K. Lundquist, and B. Kosovic, 2011: Implementation of nonlinear subfilter turbulence stress models for large-eddy simulations in the Advanced Research WRF Model. Monthly Weather Review, 138, 4212-4228.

Olson, J. B. and J. M. Brown, 2011: A Comparison of Model and Observed Turbulent Kinetic Energy Within Coastal Barrier Jets Forced by Landfall Cyclones. American Meteorological Society 24th Conference on Weather and Forecasting/20th Conference on Numerical Weather Prediction, January, 2011, Seattle, WA. Presentation available at http://ams.confex.com/ams/91Annual/webprogram/Paper182597.html

Porter, K. and J. Rogers, 2010: Status of Centralized Wind Power Forecasting in North America. NREL Technical Report NREL/SR-550-47853, available at http://nrelpubs.nrel.gov/Webtop/ws/nich/www/public/SearchForm

Skamarock, W. C. and J. B. Klemp, 2008: A time-split nonhydrostatic atmospheric model for weather research and forecasting applications. Journal of Computational Physics, 227(7):34653485 .

Storm B., J. Dudhia, S. Basu, A. Swift, and I. Giammanco, 2009: Evaluation of the Weather Research and Forecasting Model on Forecasting Low-level Jets: Implications for Wind Energy. Wind Energy, 12, 81-90.

Rhodes \& Lundquist

Page 11 of 12 
Wharton, S., and J.K. Lundquist, 2010: Atmospheric Stability Impacts on Power Curves of Tall Wind Turbines - An Analysis of a West Coast North American Wind Farm. LLNL Technical Report LLNL-TR-424435, available at https://e-reports-ext.IInl.gov/pdf/387609.pdf 